NASA Technical Memorandum 102522

\title{
Coplanar Waveguide Fed Phased Array Antenna
}

R.N. Simons

Sverdrup Technology, Inc.

NASA Lewis Research Center Group

Cleveland, Ohio

G.E. Ponchak and R.Q. Lee

National Aeronautics and Space Administration

Lewis Research Center

Cleveland, Ohio

N.S. Fernandez

University of Puerto Rico

Rio Piedras, Puerto Rico

Prepared for the

1990 IEEE AP-S International Symposium and URSI Radio Science Meeting

Dallas, Texas, May 7-11, 1990

\section{NRSA}

(NASA-TM-1U2522) COPLANAR WAVEGUIOE FEO

PHASED ARRAY ANTENNA (VASA) 6 P CSCL OSA

N90-21273 
$\Rightarrow$ 


\author{
R.N. Simons \\ Sverdrup Technology, Inc. \\ NASA Lewis Research Center Group \\ Cleveland, Ohio 44135 \\ G.E. Ponchak and R.Q. Lee \\ National Aeronautics and Space Administration \\ Lewis Research Center \\ Cleveland, Ohio 44135 \\ N.S. Fernandez* \\ University of Puerto Rico \\ Rio Piedras, Puerto Rico 00931
}

\title{
SUMMARY
}

A K-band four element linear phased array has been designed and tested. Coplanar waveguide $(\mathrm{CPW})$ is used for the microwave distribution system. A CPW to twin strip transition is used to interface with the printed dipole antennas. MMIC phased shifters are used for phase control.

\section{INTRODUCTION}

Coplanar waveguide (CPW) is a transmission line which consists of a center strip and a semi-infinite ground plane on either side of it (ref. 1). CPW is useful for integrating MMIC's together to form a microwave distribution network since the ground planes are readily accessible on the top side of the substrate. Grounded CPW (GCPW) is a variant of CPW which incorporates an additional ground plane on the back side of the substrate (ref. 2). This additional ground plane can serve as a heat sink and provide mechanical strength. In addition, this ground $p l a n e$ serves as a shield between stacked antennas boards to improve isolation.

Several CPW fed antennas have been reported in the literature. A GCPW fed coplanar stripline antenna constructed by widening the center strip of the GCPW to form a rectangular patch has been reported (ref. 3). This antenna produces a linearly-polarized pattern normal to the plane of the substrate. Coplanar waveguide fed slot antennas which are the complement to printed dipole antennas have also been reported (ref. 4). This antenna also radiates in a direction normal to the $p l$ ane of the substrate. Although end-fire antennas are required for many large phased arrays, no CPW fed end-fire antennas have been reported yet in the literature.

"Summer Student Intern at Lewis Research Center. 
In this paper we demonstrate a K-Band four element, printed dipole linear array which uses GCPW for the feed network and the integration of the MMIC phase shifters. This array radiates in the end fire direction and is suitable for large two-dimensional arrays.

\section{CIRCUIT DESCRIPTION}

The microwave distribution network and antennas is shown in figure 1 . The microwave distribution network is fed by a single coaxial transmission line. The microwave signal is then split equally onto four GCPW transmission lines by three GCPW T-junctions. Wire bonds were used to tie the ground planes of the GCPW at the bends and T-junctions. The insertion loss for the one-to-four power divider is shown in figure 2. The MMIC phase shifters are DC lsolated from the rest of the network by a pair of GCPW couplers. The couplers have been optimized to have a passband at the antenna operating frequency. The GCPW was tapered to provide a better match to the line width of the microstrip lines on the MMIC. The insertion loss for the two couplers with a GaAs 50 microstrip through connection in place of the phase shifters was $2.0 \mathrm{~dB}$. The transition from the unbalanced GCPW to the balanced coplanar strip transmission line was made through a coplanar balun (ref. 5). The circuit was fabricated on $0.0625 \mathrm{in}$. thick CuFion materlal.

The phase shifters shown in figure $3(a)$ were developed by Hughes Aircraft Corporation under contract to NASA (ref. 6). The phase shifters are reflection type and utilize a Lange coupler and two reverse biased varactor diodes to provide continuous $180^{\circ}$ phase shift. The phase shifters were characterlzed individually before integration with the antenna network. By applying blas voltages from 0 to $4 \mathrm{~V}$, $170^{\circ}$ of phase shift was obtained as shown in figure $3(b)$ with an average insertion loss of $6.15 \mathrm{~dB}$. Amplitude control can be added by the addition of MMIC amplifiers, variable attenuators, or switches.

\section{ARRAY PERFORMANCE CHARACTERISTICS}

The measured radiation pattern for a single GCPW fed printed dipole antenna is shown in figure $4(a)$. As expected, the pattern is broad due to the low gain of the antenna. The measured radiation pattern for the four element linear array is shown in figure $4(b)$. The pattern was measured with identical GaAs $50 \Omega$ microstrip through lines in place of the phase shifters. The E-plane and $H$-plane patterns have $3-d B$ beam widths of $15^{\circ}$ and $40^{\circ}$, respectively. The E-plane pattern has a shift in the main lobe which is probably due to path length differences in the feed network. The radiation pattern of the array with the MMIC phase shifters is in the process of being made.

\section{CONCLUSIONS}

A K-Band four element linear array of printed dipole antennas which demonstrates the advantages of CPW for MMIC integration and microwave signal distribution has been fabricated and tested. The radiation characteristics for the antenna is excellent. 


\section{REFERENCES}

1. C.P. Wen, "Coplanar Waveguide: A Surface Strip Transmission Line Sultable for Nonreciprocal Gyromagnetic Device Applications," IEEE Trans.

Microwave Theory Tech., vol. MTT-17, no. 12, pp. 1087-1090, 1969.

2. Y.C. Shih and T. Itoh, "Analys is of Conductor-Backed Coplanar Waveguide," Electron Lett., vol. 18, no. 12, pp. 538-540, 1982.

3. J.W. Greiser, "Coplanar Stripline Antenna," Microwave J., vol. 19, no. 10, pp. 47-49, 1976.

4. A. Nesic, "Slotted Antenna Array Exclted by a Coplanar Waveguide," Electron. Lett., vol. 18, no. 6, pp. 275-276, 1982.

5. R.E. DeBrecht, "Coplanar Balun Circuits For GaAs FET High-Power Push-Pull Amplifiers," IEEE G-MTT International Microwave Symposium Digest, New York: IEEE, pp. 309-311, 1973.

6. L.C.T. Liu, et al., "A 30-GHz Monolithic Receiver," IEEE Trans. Microwave Theory Tech., vol. MTT-34, no. 12, pp. 1548-1552, 1986.

ORIGINAL PAGE

BLACK AND WHITE PHOTOGRAPH

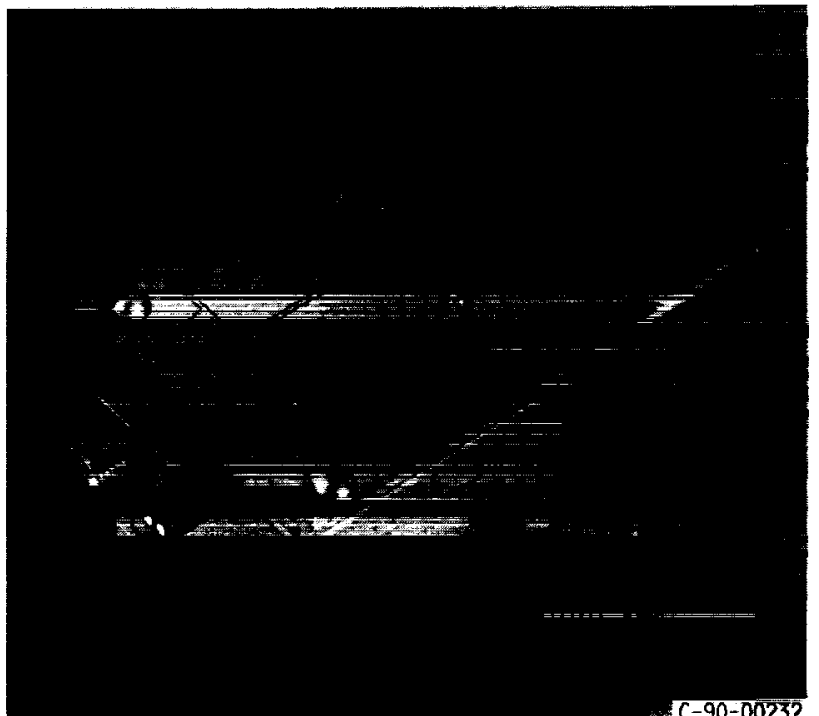

FIGURE 1. - GCPW FED FOUR ELEMENT PRINTED DIPOLE PHASED ARRAY.

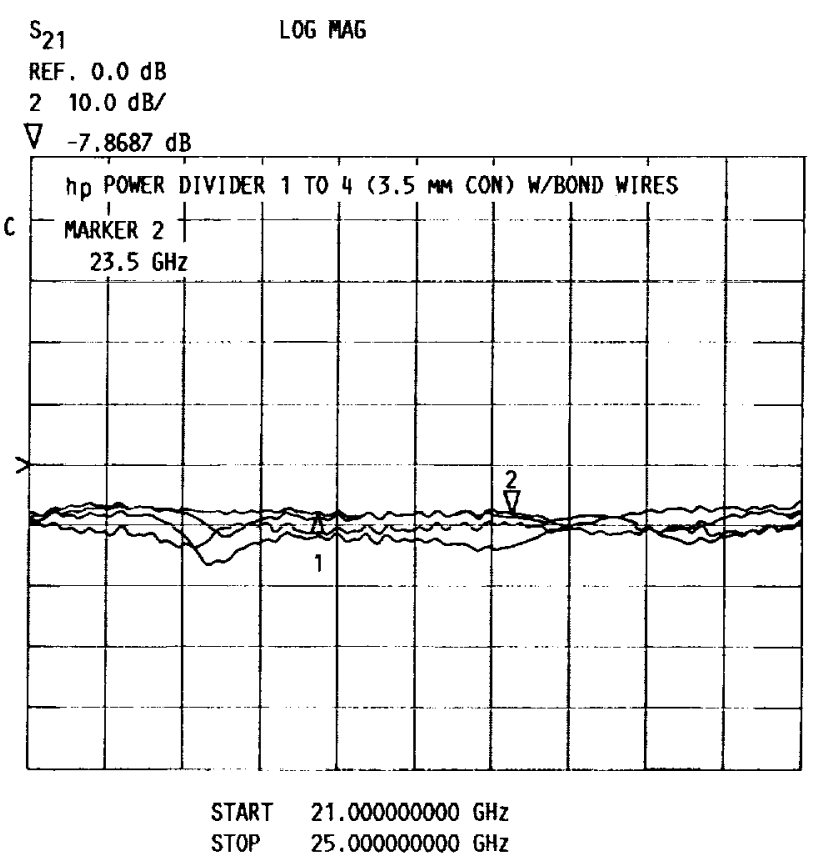

FIGURE 2. - GCPW ONE-TO-FOUR POWER DIVIDER AMPLITUDE CHARACTERISTICS. 
ORIGINAL PAGE

-BLACK AND WHITE PHOTOGRAPH

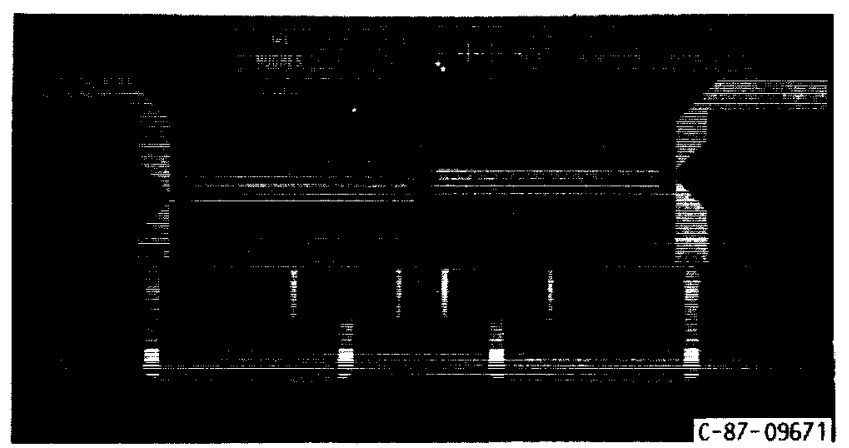

(a) PHASE SHIFTER CONFIGURATION.

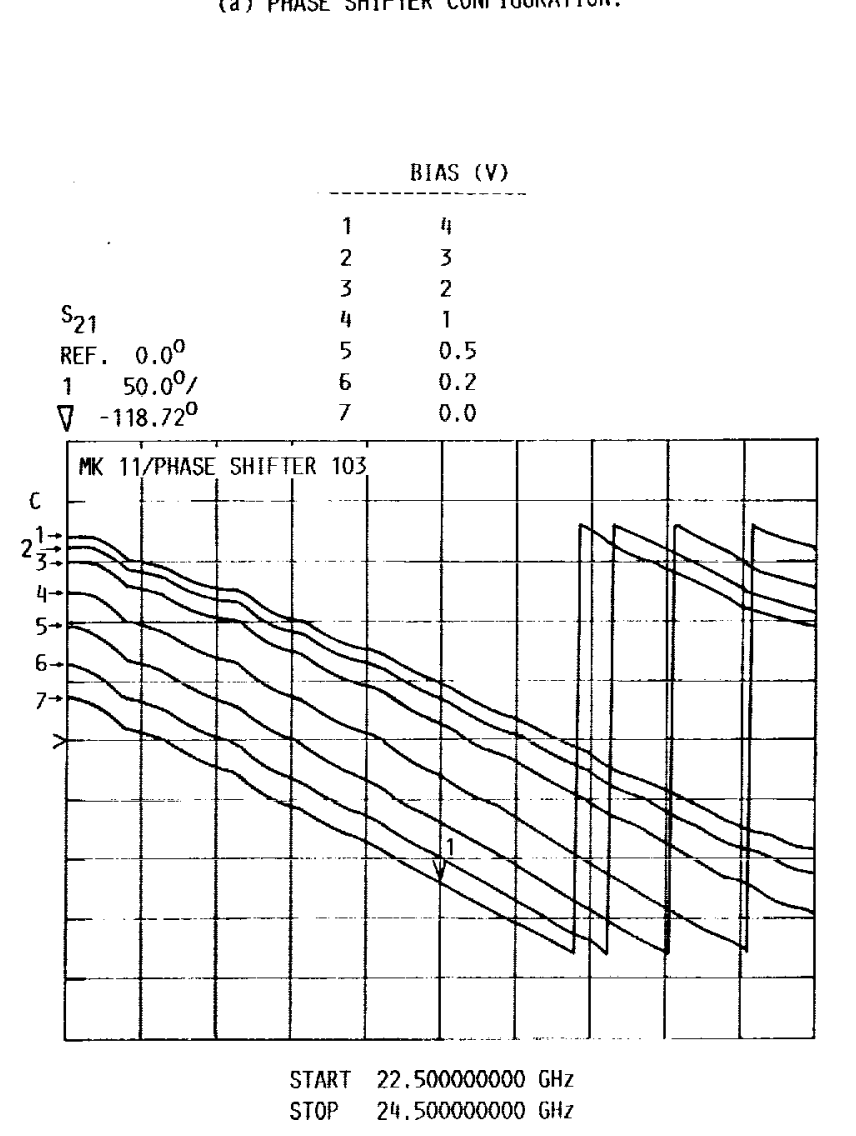

(b) MEASURED PHASE SHIFT AS A FUNCTION OF THE FREOUENCY FOR

(b) MEASURED PHASE SHIFT AS A FUNCTION OF THE FREOUENCY FOR
DIFFERENT VOLTAGES. FIGURE 3. - GaAS MMIC PHASE SHIFTER.

\section{ORIGINAL PAGE IS \\ OF POOR QUALITY}

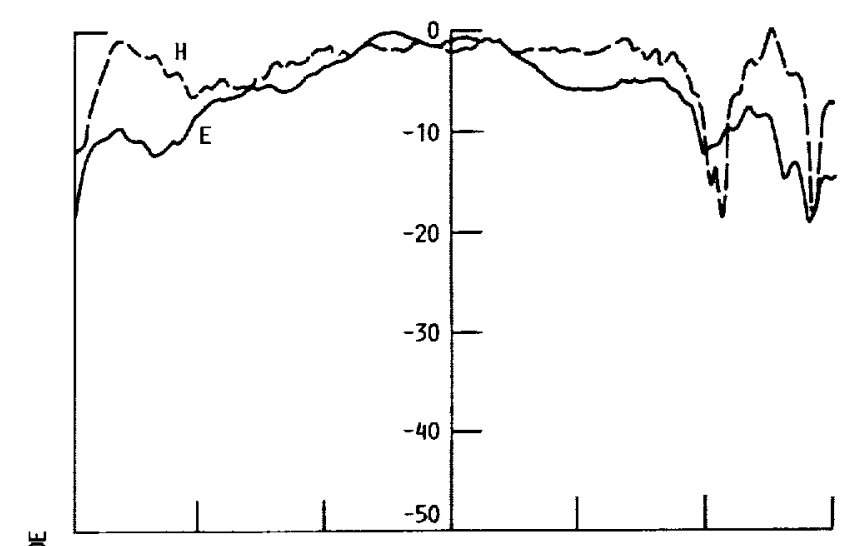

(a) E- AND H-PLANE PATTERN OF A SINGLE RADIATING ELEMENT.

恶

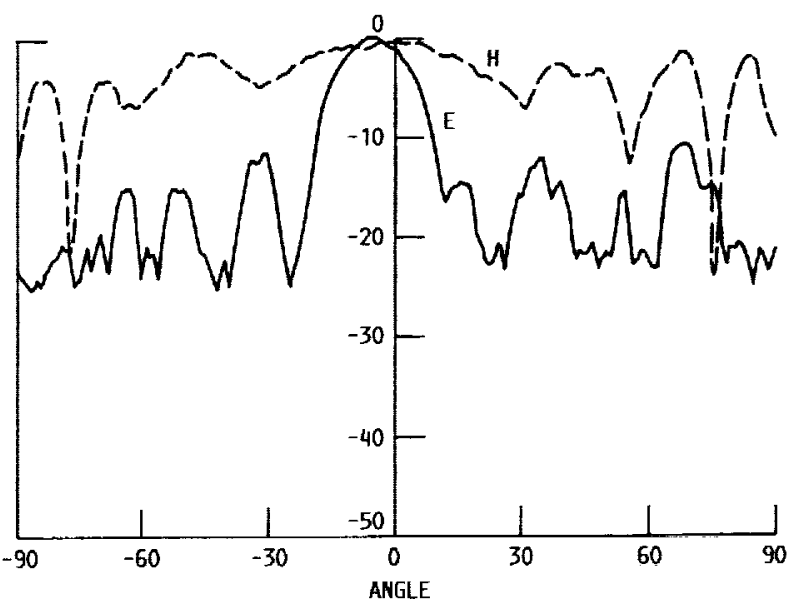

(b) E- AND h-PLANE PATtern OF THE FOUR ELEMENT ARRAY at $21.3 \mathrm{GHz}$. FIGURE 4. - MEASURED RADIATION PATTERH. 


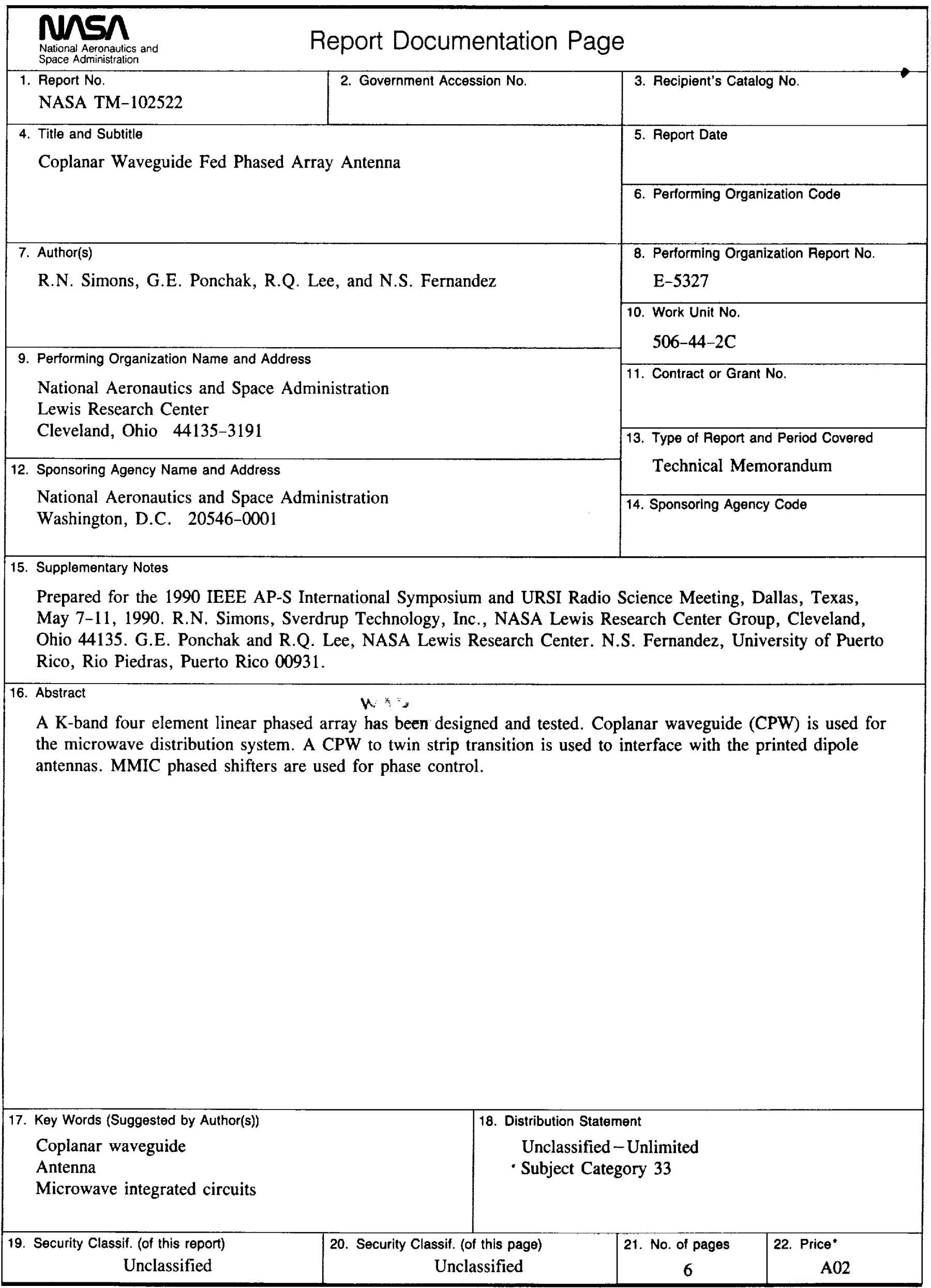


